\title{
Sarcoidosis presenting as erythema nodosum
}

\author{
Medina L. D., Valenzuela M. J., Concha D. C., Barros C. E.
}

\begin{abstract}
Introduction: Nodular lesions and painful, symmetrical, erythematous plaques located predominantly on the extensor surfaces of the lower limbs, meaning that an appropriate clinical analysis should be performed, since it involves a wide range of causes. Case Report: We present a case report of a 25-year-old male patient diagnosed with sarcoidosis. His first clinical manifestation was the appearance of lesions compatible with erythema nodosum, accompanied by polyarthralgias of inflammatory characteristics predominantly in the lower limbs. The presence of noncaseating granulomas is demonstrated in taken biopsies. Erythema nodosum is an acute septal panniculitis of subcutaneous fat without signs of true vasculitis, and is the most common clinical-pathological variety of panniculitis. Being a reactive cutaneous process, it can be triggered by a long list of infectious, inflammatory disorders, malignant neoplasms and medications. Conclusion: Erythema nodosum is usually benign, its approach requires a practice that focuses on the determination of concomitant pathologies.
\end{abstract}

Keywords: Erythema nodosum, Nodular vasculitis, Sarcoidosis, Septal panniculitis

Medina L. D. ${ }^{1}$, Valenzuela M. J. ${ }^{2}$, Concha D. C. ${ }^{1}$, Barros C. E. ${ }^{1}$

Affiliations: ${ }^{1}$ Internal Medicine Department, Hospital Universitario La Samaritana, Colombia; ${ }^{2}$ Internal Medicine Resident, Universidad de la Sabana, Colombia.

Corresponding Author: Camilo Barros Gutierrez, Internal Medicine Department, Hospital Universitario La Samaritana, Colombia; Email: camilo_barros@hotmail.com

Received: 26 May 2018

Accepted: 02 July 2018

Published: 28 July 2018

\section{How to cite this article}

Medina LD, Valenzuela MJ, Concha DC, Barros CE. Sarcoidosis presenting as erythema nodosum. Int $\mathrm{J}$ Case Rep Images 2018;9:100942Zo1ML2018.

Article ID: 100942Z01ML2018

$* * * * * * * * *$

doi: 10.5348/100942Zo1ML2018CR

\section{INTRODUCTION}

Sarcoidosis is a multisystem granulomatous, noncaseating disease; the skin is the second most affected organ, considering its involvement between 25 to $30 \%$ of cases [1]. The prevalence may vary, being more frequent in African-American people, in women than in men; with incidence peaks between 25 and 45-year-old [2]. The skin lesions developed from it, can be varied, being generally classified as "specific", when typical histopathological findings are found, as are granulomatous infiltrates; and "non-specific".

Among the first ones are included lesions such as macules, papules, plaques, nodules, subcutaneous lesions, lupus pernio, among others. Among non-specific lesions, the most common is the erythema nodosum; being reported in up to $25 \%$ of cases; it is manifested as painful, erythematous lesions on extensor surfaces of the limbs; they can usually resolve spontaneously in a period of 1 to 3 weeks, without complications; but in some cases there may be a recurrence [3]. In this article we describe a case of a young adult, in whom erythema nodosum was the first manifestation of sarcoidosis.

\section{CASE REPORT}

A 25-year-old male patient consulted the emergency department for a clinical picture of two months evolution of the appearance of painful erythematous lesions on the anterior aspect of both legs, which later spread 


\section{EDORIUM Journals}

to the trunk and the posterior aspect of the forearms. Subsequently, the patient presented polyarthralgias of inflammatory characteristics, which started in the ankles and knees and advanced symmetrically to elbows and radiocarpal joints, without the presence of synovitis. The patient did not report significant clinical history. Physical examination revealed erythematous plaques on extensor surfaces of both legs (Figure 1), extensor forearm surfaces (Figure 2), between 2 and 11 centimeters, non-confluent, with random distribution, painful on palpation, with local temperature increase. Right inguinal adenopathy of approximately $3 \mathrm{~cm}$ was palpable, painful on palpation, rubbery consistency, slightly fluctuating (not adhered to deep layers).

Paraclinical studies were performed, finding a complete blood count (CBC): leukocytes 6780/ul, with neutrophils 62.2\%, lymphocytes 24\%, hemoglobin $14.4 \mathrm{~g} / \mathrm{dL}$ and platelets 315000 / ui; with elevated erythrocyte sedimentation rate (ESR): $30 \mathrm{~mm} / \mathrm{h}$ (o-10 $\mathrm{mm} / \mathrm{h}$ ), C-reactive protein (CRP): $3.9 \mathrm{mg} / \mathrm{dL}$. (O-10 mg/ dL). Blood tests for urea, creatinine, electrolytes, liver function tests, sugar did not revealed any abnormality. Enzyme-linked immunosorbent assay (ELISA) for HIV 1 and 2 were negative, hepatitis b antigen surface nonreactive, Hepatitis $\mathrm{C}$ antibody non-rapid plasma reagin (RPR) non-reactive. The results of the skin and lymph node biopsy (Figure 3) show noncaseating granulomas with giant cells type Langhans, and negative stains for acid-fast bacilli.

Once the presence of noncaseating granulomas was found in the biopsy, treatment was started with prednisolone at a dose of $0.6 \mathrm{mg} / \mathrm{kg} /$ day (35 mg), which was sustained for 4 weeks; period in which there was improvement of signs and symptoms presented. Because of the clinical improvement the dose was reduced every 4 weeks until reaching a maintenance dose of $0.2 \mathrm{mg} / \mathrm{kg} /$ day (10 mg); without documenting adverse effects before treatment.

\section{DISCUSSION}

Erythema nodosum (EN) is an acute septal panniculitis of subcutaneal fat without signs of true vasculitis [4], and is the most common clinical-pathological variety of panniculitis [5]. Its first histopathology description was performed in 1949 by Löfgren and Walgren in 64 cases [6]. It can be of idiopathic etiology, in many cases, but it can also be the first sign of a systemic disease, so it is important to identify the baseline, in order to establish a specific etiological treatment [7].

It has been considered that EN is the result of a nonspecific cutaneous reaction to various antigens, so the mechanism involved would be immune-mediated [8]. Based on this, it has been suggested that it may be the result of the formation of immune complexes and their deposition around the septa vessels of the connective tissue of the subcutaneous cellular tissue, and it has

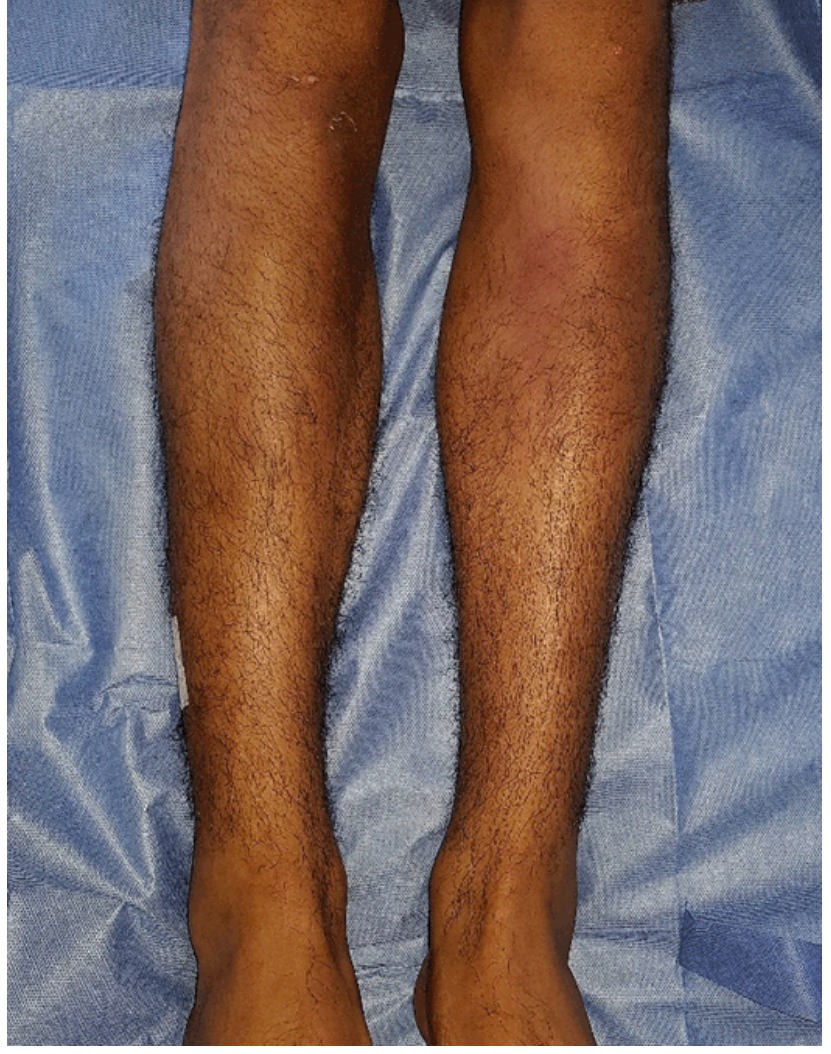

Figure 1: Erythematous lesions type plaque in lower extremities, extensor surface between 2 to 11 centimeters.

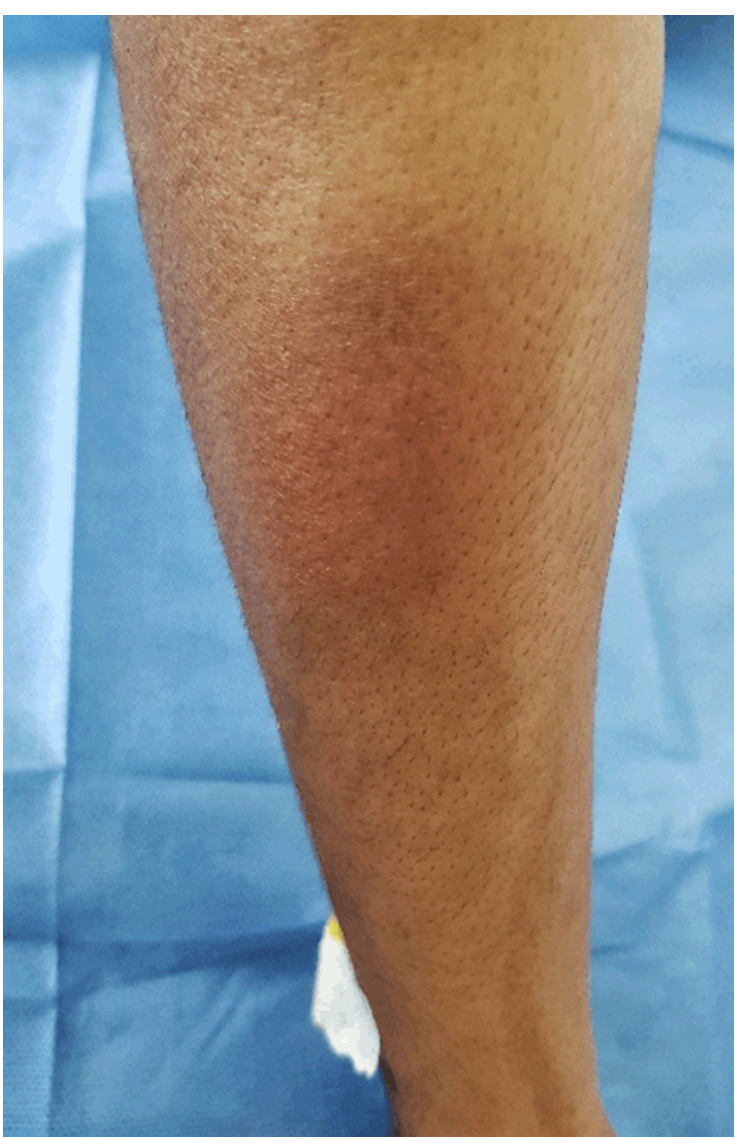

Figure 2: Erythematous lesion on extensor surface of the left forearm. 


\section{EDORiUM Journals}

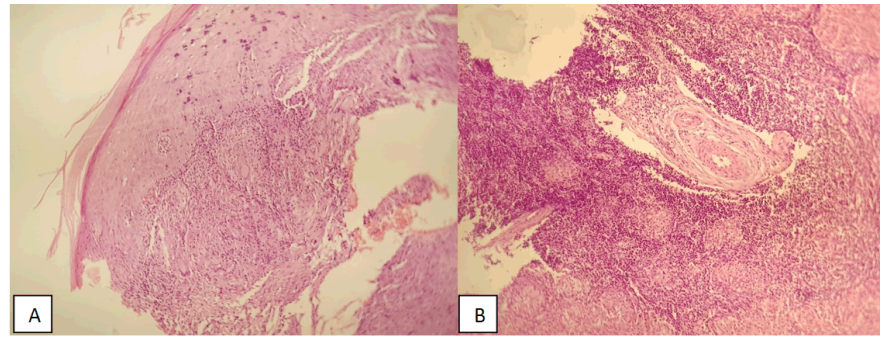

Figure 3: A: Skin biopsy. Hematoxylin stain - Eosin.Hyperplastic squamous epithelium, papillary and reticular dermis with presence of noncaseating granulomas with Langhans giant cells. B: Lymph node with presence of noncaseating granulomas.

been possible to demonstrate the presence of circulating immunocomplexes and activation of the complement [9]. Additionally, histopathological features and numerous direct and indirect tests support the idea of a delayed type IV hypersensitivity response to many antigens. Likewise, direct immunofluorescence studies have shown deposits of immunoglobulins in blood vessels [5].

Erythema nodosum occurs most often in women between 25 and 40 years old with a maximum incidence between 20 and 30 years old, but can be observed at any age, being 3-6 times more common in women than in men [7]. It has an annual incidence that ranges between 1 and 5 cases per 100,000 habitants. The etiological factors show considerable geographical variations depending on the specific endemic infections in each country, as well as other conditioning factors [7]. Histopathology shows a reaction, in which perivascular neutrophilia with septal panniculitis is observed in the deep dermis and subcutaneous tissue, without affecting the epidermis. It has been shown that histopathological findings are common regardless of the etiology of EN [10].

Being a reactive cutaneous process can be triggered by a long list of infectious, inflammatory disorders, malignant neoplasms and medications. Among the most frequent causes are the infectious ones, being the infection by the Beta-hemolytic streptococcus 10 to $60 \%$ of the cases in the published series. Among the less frequent, Yersinia gastroenteritis as a predominant cause in children, followed by tuberculosis, leprosy, post-streptococcal infections, Yersinia gastroenteritis, Salmonella, Campylobacter; Leptospirosis, Brucellosis, Chlamydia trachomatis, Mycoplasma, Psittacosis, brucellosis, syphilis. Fungal infections, among which are histoplasmosis, primary Coccidioidomycosis, Blastocitomycosis; In the same way, viral infections of Hepatitis B virus and infectious Mononucleosis, among others, may be secondary. Erythema nodosum secondary to the use of medications has been described, but although they are cited, it is difficult to prove it in clinical practice $[4,11]$.

Acetylsalicylic acid, Sulfonamides, Penicillins, Oral contraceptives and Inhibitors of Tumor Necrosis Factor alpha (TNF $\alpha$ ) have been implicated. Well-documented cases are extremely rare so a recurrent presentation in relation to intake can be an element of guidance [9]. Some neoplastic processes have been related to the production of the same, highlighting the leukemias, and within them the acute myeloid variety; and lymphomas, being more frequent in Hodking lymphomas. Diseases such as sarcoidosis, Sweet's syndrome, Behcet's disease, Whipple's disease; and inflammatory bowel disease (both ulcerative colitis and Crohn's disease) have also been documented as causing erythema nodosum. Another very rare but described cause is pregnancy in which the EN occurs recurrently, but in up to $50 \%$ of cases the cause is unknown $[4,11]$.

The clinical manifestations usually show an acute and self-limiting onset, characterized by the sudden appearance of nodules and erythematous plaques, which are located predominantly on the extensor surfaces of the lower extremities, with a size range of 1 to $5 \mathrm{~cm}$; the lesions have a bilateral and symmetric distribution, typically show spontaneous regression, without ulceration, scarring or atrophy and, in general, patients present recurrent episodes [5]. In its natural course, a prodromal phase is usually present, 1 to 3 weeks before the onset of the lesions; where fever, myalgia and arthralgia are evident [12]. Less frequent manifestations related to erythema nodosum are: lymphadenopathies, hepatomegaly, splenomegaly and pleuritic pain [13].

The reason why the anterior side of the legs are so susceptible to developing lesions is unknown, some authors have proposed that there is no other site on the surface of the skin where the combination of a relatively scarce arterial supply is associated with a venous system subject to gravitational and cooling effects, and a lymphatic system that is barely rich enough to meet the requirements of any increase in fluid loading and that has no mechanical stimulus [5].

P. Varas et al, in their study published in 2016, which assessed the most prevalent causes of patients hospitalized for erythema nodosum, found that $84.6 \%$ were women, maintaining the relationship described in the literature of $6: 1$; more than $60 \%$ of the patients presented fever, $74 \%$ with arthralgia and $21 \%$ had cough; they consulted mainly for cutaneous involvement, finding bilateral lesions in the lower extremities as our patient; $68.1 \%$ of the cases were considered secondary, of which the infectious causes and sarcoidosis were more frequently described in $11 \%$ [14].

The diagnosis of EN is mainly clinical and once it has been carried out, an accurate anamnesis must be filled out according to each etiology described (possible exposure to tuberculosis, fever, bloody diarrhea, abdominal pain, previous respiratory infection, dysphagia, etc.), in this way, the physical examination associated signs should be sought. When the case is considered typical, it is not necessary to carry out complementary studies to confirm that it is an EN [14], but in all cases, the next step is the etiological evaluation that should include tests according to clinical orientation. The biopsy should be reserved only in cases of diagnostic doubt. The Initial evaluation 


\section{EDORIUM Journals}

should include complete blood count, determination of acute phase reactants such as sedimentation rate, antistreptolysin $\mathrm{O}$ titer, urinalysis, throat culture, intradermal tuberculin test, and a chest imaging [5]. In the typical findings, the white blood count is normal or only slightly raised, but the erythrocyte sedimentation rate is often high, returning to normal when the eruption subsides. In children, the elevation of the erythrocyte sedimentation rate correlates significantly with the number of cutaneous lesions [15].

The treatment of erythema nodosum should be directed to the underlying associated condition, if identified. Normally, EN nodules improve spontaneously within 3 to 6 weeks, indicating prolonged rest and cessation of work activities, which is usually sufficient. Non-steroidal anti-inflammatories may be useful to optimize analgesia [4]. In cases of orthostatism, venous compression stockings, which reduce pain, may be required. If the lesions persist for a longer time, it has been reported that the use of potassium iodide in a dose of 400 to $900 \mathrm{mg}$ daily or a saturated solution of potassium iodide, from 2 to 10 drops in water or orange juice three times a day is useful; the mechanism of action of potassium iodide in erythema nodosum is unknown, but it seems to cause the release of heparin from mast cells and heparin acts to suppress delayed hypersensitivity reactions [5]. Systemic corticosteroids are rarely indicated in erythema nodosum and, prior to the administration of these drugs, an underlying infection should be ruled out. The intralesional injection of triamcinolone acetonide in the center of the nodules may cause them to resolve. Some patients may respond to a course of colchicine, from 0.6 to $1.2 \mathrm{mg}$ twice a day. In cases of secondary EN, etiological treatment is essential $[5,16]$.

\section{CONCLUSION}

The erythema nodosum is usually benign, with a favorable evolution, which per se is a rarely diagnosed condition and its approximation requires a practice that focuses on the determination of concomitant pathologies. Its finding is a diagnostic challenge for the physician who is in charge of evaluating the patient. In the present case, it was possible to determine that EN was presented as a manifestation of an underlying and relevant clinical condition, such as sarcoidosis.

\section{REFERENCES}

1. Wanat KA, Rosenbach M. Case series demonstrating improvement in chronic cutaneous sarcoidosis following treatment with TNF inhibitors. Arch Dermatol 2012 Sep;148(9):1097-100.

2. Sanchez M, Haimovic A, Prystowsky S. Sarcoidosis. Dermatol Clin 2015 Jul;33(3):389-416.
3. Lodha S, Sanchez M, Prystowsky S. Sarcoidosis of the skin: A review for the pulmonologist. Chest 2009 Aug;136(2):583-96.

4. Mert A, Kumbasar H, Ozaras R, et al. Erythema nodosum: An evaluation of 100 cases. Clin Exp Rheumatol 2007 Jul-Aug;25(4):563-70.

5. Requena L, Yus ES. Erythema nodosum. Dermatol Clin 2008 Oct;26(4):425-38.

6. Lofgren S, Wahlgren F. On the histopathology of erythema nodosum. Acta Derm Venereo 1949;129:1.

7. Molina-Ruiz AM, Requena L. Erythema nodosum. [Article in Spanish]. Med Clin (Barc) 2016 Jul 15;147(2):81-6.

8. Hedfors E, Norberg R. Evidence for circulating immune complexes in sarcoidosis. Clin Exp Immunol 1974 Mar;16(3):493-6.

9. Jones JV, Cumming RH, Asplin CM, Laszlo G, White RJ. Letter: Circulating immune complexes in erythema nodosum and early sarcoidosis. Lancet 1976 Jan 17;1(7951):153.

10. Mana J, Marcoval J. Erythema nodosum. Clin Dermatol 2007 May-Jun;25(3):288-94.

11. García-Porrúa C, González-Gay MA, VázquezCaruncho M, et al. Erythema nodosum: Etiologic and predictive factors in a defined population. Arthritis Rheum 2000 Mar;43(3):584-92.

12. Gilchrist H, Patterson JW. Erythema nodosum and erythema induratum (nodular vasculitis): Diagnosis and management. Dermatol Ther 2010 JulAug;23(4):320-7.

13. Psychos DN, Voulgari PV, Skopouli FN, Drosos AA, Moutsopoulos HM. Erythema nodosum: The underlying conditions. Clin Rheumatol 2000;19(3):212-6.

14. Varas P, Antúnez-Lay A, Bernucci JM, Cossio L, González S, Eymin G. Erythema nodosum: Analysis of 91 hospitalized patients. [Article in Spanish]. Rev Med Chil 2016 Feb;144(2):162-8.

15. Kakourou T, Drosatou P, Psychou F, Aroni K, Nicolaidou P. Erythema nodosum in children: A prospective study. J Am Acad Dermatol 2001 Jan;44(1):17-21.

16. Descamps V, Bouscarat F. Cutaneous manifestations of sarcoidosis. [Article in French]. Ann Dermatol Venereol 2016 Jan;143(1):39-50.

$* * * * * * * * *$

\section{Author Contributions}

Medina L. D. - Substantial contributions to conception and design, Acquisition of data, Analysis and interpretation of data, Drafting the article, Revising it critically for important intellectual content, Final approval of the version to be published

Valenzuela M. J. - Substantial contributions to conception and design, Acquisition of data, Analysis and interpretation of data, Drafting the article, Revising it critically for important intellectual content, Final approval of the version to be published

Concha D.C. - Substantial contributions to conception and design, Acquisition of data, Analysis and interpretation 
www.ijcasereportsandimages.com

of data, Drafting the article, Revising it critically for important intellectual content, Final approval of the version to be published

Barros C. E. - Substantial contributions to conception and design, Acquisition of data, Analysis and interpretation of data, Drafting the article, Revising it critically for important intellectual content, Final approval of the version to be published

\section{Guarantor of Submission}

The corresponding author is the guarantor of submission.

\section{Source of Support}

None.

\section{Consent Statement}

Written informed consent was obtained from the patient for publication of this case report.

\section{Conflict of Interest}

Authors declare no conflict of interest.

\section{Copyright}

(C) 2018 Medina L. D. et al. This article is distributed under the terms of Creative Commons Attribution License which permits unrestricted use, distribution and reproduction in any medium provided the original author(s) and original publisher are properly credited. Please see the copyright policy on the journal website for more information.
Access full text article on other devices

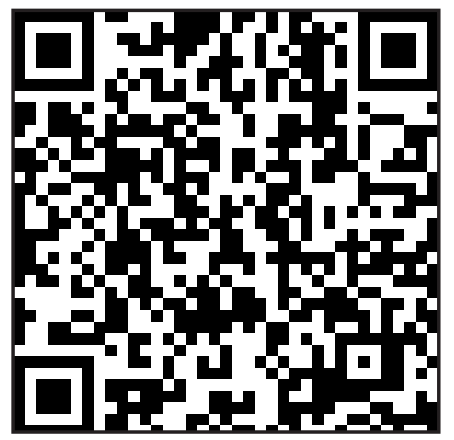

Access PDF of article on other devices

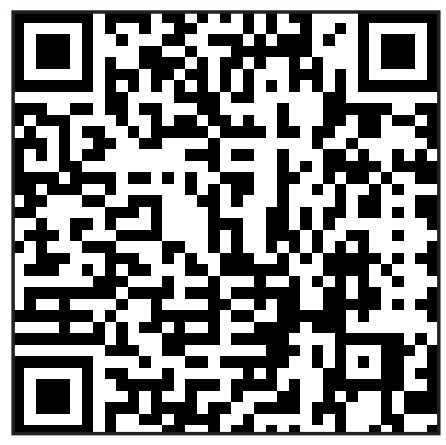

